\title{
"Y ASÍ, A TODOS OS RECIBO A PRUEBA»: RISA E IDEOLOGÍA EN "EL JUEZ DE LOS DIVORCIOS" DE CERVANTES
}

Los primeros años del siglo XVII constituyen una época de crisis ideológica en España; se afianza una visión del mundo teocéntrica de estirpe medieval, a la vez que comienza el movimiento hacia la edad moderna. Aunque inicialmente la tendencia reaccionaria parece imponerse, se entabla un diálogo entre tradición y cambio. El ambiente de censura que reina en la península obliga a que cualquier tendencia disidente se articule casi siempre de manera indirecta. Cervantes explota las posibilidades subversivas del entremés, género que puede llevar una crítica velada bajo el manto de una comicidad en apariencia inofensiva y que permite explorar bajo una óptica deformante, como señala Spadaccini, algunas zonas de la realidad que apenas se exploran en la Comedia (74).

Para el lector moderno, la función crítica de los entremeses cervantinos resulta evidente, puesto que, alejado de la cultura del siglo XVII, su experiencia como lector no produce una risa automática, sino que desemboca en una meditación del por qué y del cómo de la risa en el siglo XVII ${ }^{1}$. Si consideramos la risa en tanto que fenómeno social, nuestra lectura de El juez de los divorcios se convertirá de manera inevitable en una exploración de la ideología y de la sociedad de la época.

En este entremés de Cervantes se entretejen la acción, las ideas y la risa para crear una ambigüedad de sentido que pone en tela de juicio la validez de la aplicación inflexible de las re-

${ }^{1}$ Afirma IAN DONALDSON: *...to explore... the comedy of an age other than our own is often to be moved not so much to spontaneous laughter as to questions about laughter* (1). 
glas que rigen la indisolubilidad del matrimonio cristiano. Queremos explorar la ambigüedad ideológica de la obra por medio de un análisis de la risa fundado en las teorías de la época sobre la comicidad y llevado a cabo dentro del marco socio-cultural del siglo XVII. Para estos fines, daremos una visión general de la controversia sobre el divorcio desde Erasmo hasta las decisiones definitivas del Concilio de Trento e investigaremos las secciones sobre la comicidad de las Tablas poéticas de Francisco Cascales y de la Philosophia antigua poética de Alonso López Pinciano.

La doctrina de la Iglesia Católica sobre el divorcio se basa en unas cuantas referencias bíblicas de las que son representativas las siguientes líneas de la Primera Epístola a los Corintios: "A los que se casaron les ordeno, y en realidad la orden es del Señor, que la mujer no se separe de su marido. Y si se separa que no vuelva a casarse o que haga las paces con su marido. Lo mismo, que el marido no despida a su mujer" (1 Cor. vii.10-12 ${ }^{2}$. La doctrina de la indisolubilidad del matrimonio que proscribe el divorcio y la posibilidad de nuevas nupcias se afianza bajo la autoridad de San Agustín, y toma forma definitiva en la obra de Santo Tomás de Aquino ${ }^{3}$. El Concilio de Trento, en la sesión veinticuatro del once de noviembre de 1563 , ratifica la calidad de sacramento del matrimonio y en consecuencia, su indisolubilidad (Olsen, 38).

En su emblema "Violentum matrimonium», Hernando de Soto resume la posición de la Iglesia haciendo referencia específica al Concilio de Trento:

Tiene el matrimonio tanta fuerça, que haze de dos vno, y de dos voluntades vna: de suerte, q[ue] supuesto el amor y obediencia, que está obligada a tener la muger al marido por ser superior suyo. Los maridos han de amar a sus mugeres de la forma que Christo amo a su Iglesia: y de tal manera se han de amar el vno y el otro, que por este amor han de olvidar padre y madre. Este lazo perpetuo (segun se difinio en el santo Concilio de Trento) requiere para tener el efecto debido, libre consentimiento y voluntad, porque es vna de las partes necessario del... porque... el Matrimonio es vinculo, que durante la vida, no se puede desatar, ni romper, y que la muerte sola puede deshazerles... (51v-52r)

No deja de dar Soto una nota inquietante a través del grabado que representa

${ }^{2}$ Otras declaraciones bíblicas importantes sobre el divorcio se encuentran en Mateo v.32, Mateo xix.9, Marcos x.11-12, Lucas xvi.18, y Corintios i.15 como lo indica OLSEN (1-43).

${ }^{3}$ Para la historia del matrimonio como sacramento en la tradición occidental, ver el primer capítulo del libro de OLSEN (2-43), 
dos culebras siempre enlazadas sin poderse apartar. En que nos da a entender que la contrariedad suya, que fuera de que cada dia se veen semejantes casamientos, sola la imaginación de que los dos tendrian perpetuamente desconformidad, siendo imposible apartarse en vida, bastara para dar pesadumbre, quanto más sucediendo de ordinario como he dicho, y ser forçoso el auer de sufrir tal martirio los que llegaren a ser desconformes casados (o por mejor decir, descasados conformes) y con ello a ser tan desgraciados (52r-52v)

No cuestiona Soto la doctrina eclesiástica, pero nos pinta un cuadro desconsolador de la situación de los malcasados, condenados a perpetua disconformidad, que evoca el estado de las parejas del entremés cervantino.

Casi un siglo antes de la publicación del libro de Soto, el tema del divorcio cobra gran vitalidad a causa de unos comentarios de Erasmo que cuestionan la doctrina eclesiástica. Los puntos principales de las ideas de Erasmo sobre el divorcio se encuentran en la nota a 1 Corintios vii de su edición del Nuevo Testamento ${ }^{4}$. Erasmo comparte la preocupación de Soto por la situación de los miles de malcasados ${ }^{5}$ y propone que aunque la única causa de divorcio que Cristo acepta es el adulterio, San Pablo, enfrentado con la imperfección de la humanidad, ensancha los preceptos del Señor ${ }^{6}$. A Erasmo le horroriza que el matrimonio se tome a la ligera llevándose a cabo entre jovencitos inmaduros, o por medio de terceras, o entre tontos y borrachos, y que, sin embargo, se considere en estos casos como uno de los siete Sacramentos ${ }^{7}$. La nota a 1 Corintios vii propone cambiar las leyes del matrimonio para permitir el divorcio cuando haya causas válidas y para permitir la posibilidad de nuevas nup-

4 Utilizamos para este artículo la traducción de Nicholas Lesse al inglés de la nota de Erasmo a 1 CoR. vii. La edición que seguimos no tiene numeradas las páginas, y, por lo tanto, las referencias que damos reflejan nuestra propia numeración.

5. «...for we do se many thousands so unluckelye copeled togyther, wyth as euyl agrement, that bothe partes do peryshe thereby, which (peradventur) might be saved, if they had bi let asonder one from the other... (ERASmo 12-13).

6 Christ dothe restrayn the separation of man and wyfe to won cause only, not that there ar not greater offences and more gruos offences tha[n] adultery, but bycause whordom in wedlok is all manner of ways repognant and dyrectly contrary to the state of matrymony* (ERASMo 90).

*... and yet Paul dothe beare with the meaness of man, enlargin often time the precept of the lord" (ERASMo 91).

7 *Among Christi[an] $\mathrm{m}[\mathrm{en}]$, marriage is exceding lightly made, and after it is ons mad, it can not be undone agayne, for matrimony is contracted secretely in corners, after a stealyng..., betweene boys and yonge wenches, by the helpe of baudes and whoares: it is contracted between fooles and dronkards and yet this shameful contract cannot be undone, yea... they do make of this fylthy and ungodly contracte an holy sacrament...* (ERASMO 92-93). 
cias $^{8}$. Tales ideas suscitan acusaciones, entre ellas las de un grupo de frailes españoles:

escribe [Erasmo] cosas peores y más peligrosas... en la Primera a los Corintios, cap. VII, cuando trata de convencer de que mejor haría la Iglesia si dirimiese por numerosas causas los matrimonios consumados, dando licencia incluso a los separados para casarse de nuevo (en Avilés, 61) ${ }^{9}$

Aunque de acuerdo con la doctrina eclesiástica el matrimonio duraba hasta la muerte, la iglesia permitía dos tipos de divorcio: el 'divortium a mensa et thoro', o separación de cuerpos, y el 'divortium a vinculo matimonii' o anulación (Olsen, 18). Fuera de la tradición eclesiástica, el matrimonio tiene raíces en el derecho romano y es un contrato social de naturaleza comercial ${ }^{10}$. Cuando las obligaciones del contrato se rompen, casi siempre por razón de adulterio, aunque a veces por otras como locura furiosa, tentativa de asesinato o crímenes 'contra natura' ", se puede pedir en los siglos XVI y XVII el 'divortium a mensa e thoro' que consiste en que los casados lleven una vida separada sin posibilidades de nuevas nupcias tal como lo prescribe la ley canónica. Este tipo de divorcio es el que pide el marido de Minjaca cuando sugiere que la mejor solución es la de meterse en un convento: «...hagamos una cosa: enciérrese ella en un monasterio, y yo en otro; partamos la hacienda, y de esta suerte podemos vivir en paz... (101) ${ }^{12}$. Tal solución no es aceptable para su consorte que replica: “iBonica soy yo para estar encerra-

${ }^{8}{ }_{\alpha}$ Let us se whyther it be lawful, yea or naye, that some sorte of mariage should be undone, not wythoute a good ground... by the governors of the churche, and lawful iudges, and that the same matrimony sholde so be dissolved, that both paties might mary againe...* (ERASMo 9-10).

Para un tratamiento más completo sobre las ideas de Erasmo sobre el divorcio en el contexto de la Reforma y la Contrarreforma, ver el libro de Norskov V. Olsen y el libro de Emile V. Telle.

${ }^{9}$ El grupo de frailes españoles compone un libelo acusatorio contra varias de las ideas de Erasmo para la Conferencia de Valladolid de 1527. Erasmo responde en su Apologia ad monachos hispanos. Ver el estudio de Mrguel Avilés sobre el debate entre Erasmo y los frailes españoles que incluye una traducción del Libelo de Valladolid.

10 Estrella Ruiz-Galvez Priego establece en su excelente libro sobre la posición socio-jurídica de la mujer en la España del siglo XVI, que el matrimonio tiene un carácter de contrato comercial que está conforme con el contrato de compra y venta del derecho romano (261-390).

" Para más información sobre la ruptura de la sociedad conyugal, véase el libro de Ruiz-Galvez Priego, cap. III (323-390).

12 Sacamos todas las citas del entremés de la edición de los entremeses de Cervantes de Nicholas SPADACCINI. 
da!» (101). La separación de cuerpos se llevaba a cabo en casos extremos y los jueces, como el juez del entremés, evitaban dar una sentencia de separación. Erasmo es revolucionario en proponer un divorcio en el sentido moderno de la palabra con la posibilidad de nuevas nupcias, al menos para el miembro de la pareja que no sea culpable del divorcio ${ }^{13}$.

Aunque la oposición del Concilio de Trento al divorcio y a las tesis erasmianas da fin a la historia de la interpretación Católica de la doctrina del Nuevo Testamento sobre el divorcio (Olsen, 40), Cervantes somete a nuevo examen el tema en su entremés de $E l$ juez de los divorcios cuyo carácter cómico disfraza dudas sobre la norma tridentina ${ }^{14}$. El entremés no propone una crítica abierta como la de Erasmo contra la posición eclesiástica sobre el divorcio, pero va más allá de la nota de inquietud del emblema de Soto. El juez de los divorcios no se encuentra entre ambas posiciones ni de manera revolucionaria ni reaccionaria, sino entablando un diálogo de tono humanitario y pragmático, como el de Erasmo, que cuestiona la fría aplicación de las leyes canónicas mientras que apoya el ideal.

Cervantes lleva a cabo esta tarea a través de un entremés con una acción bastante estática donde la risa no tiene su fuente primaria ni en los gestos ni en los movimientos de los personajes. El ritmo de este entremés que, como señala Asensio, vacila entre el ritmo rápido de entremés y el «sosiego razonador inherente a la novela" (107), es testigo de la intención analítica de Cervantes. Este ritmo un poco más sosegado que el de otros entremeses tiene el efecto de que el espectador fije la atención en las secuencias verbales, no quedando relegado al papel de receptor pasivo de acciones cómicas que producen una risa automática, y que tenga que ponerse en contacto, aunque sea de manera mínima, con la carga ideológica del entremés para así darse cuenta del alcance profundo de su humor. El efecto de suscitar dudas es aun más eficaz en un lector que puede leer reflexionando y volviendo atrás que en un espectador que se enfrenta con una secuencia irreversible de diálogo y acciones.

Esta risa no automática implica una complejidad ideológica mayor que la de tantos entremeses en donde la risa es el resultado de payasadas, golpes y porrazos. Spadaccini en su introducción a los entremeses de Cervantes explica que

${ }^{13}$ Refiriéndose a Erasmo, Telle dice que «pour la première fois, le concept du divorce (a sens moderne) est lancé dans le monde" (209). Telle resume la nota de Erasmo a 1 Cor. vii. y presenta un excelente análisis de su posición con respecto al divorcio (205-231).

14 Para un estudio global del pensamiento de Cervantes sobre el matrimonio ver el artículo de MARCEl Bataillon *Cervantes y el matrimonio cristiano*. 
bajo el ritmo jocoso y festivo de las farsas entremesiles cervantinas, a través de los diálogos estrafalarios de 'personajes-tipos', se esconden ideas sobre España. Las ideologías de la España de principios del XVII 'entran en los textos', aunque sea de modo indirecto. Las burlas tienen, en último término, contenido ideológico (39).

El entremés de El juez de los divorcios no es, pues, una obrilla transparente como lo ha querido ver parte de la crítica, sino, como Mary Gaylord Randel señala, una en la cual es difícil encontrar una base sólida en su movimiento irónico (84). La posición de la obra con respecto al divorcio y al matrimonio cristiano es fluida y nunca encuentra un centro fijo. Esta ambigüedad está en la base del humor de la obra cuyo diálogo entre discurso dominante y discurso subversivo refiere al receptor a un plano ideal y a otro real sin permitir una síntesis.

Stanislav Zimic indica que la ambigüedad de este entremés también se perfila en su estructura con la ayuda "[del] remate abrupto y tan extrañamente jovial [de la obra] con respecto a las tempestuosas escenas anteriores [que] ha dejado siempre muy perplejos a los críticos" (4). Hay un grupo de críticos-Klein, Agostini-que piensan que el entremés establece una defensa del matrimonio cristiano (Rozenblat, 1). Casalduero se separa un poco de los críticos anteriores porque ve una profunda ironía en la canción final, aunque cree que el entremés está en favor de una paz ideal (196). Rozenblat, no contento con la perpleja canción final, acepta su naturaleza convencional y trata de explicar el entremés por medio de una crítica de tipo biográfico en su artículo "¿Por qué escribió Cervantes El juez de los divorcios?». Según Rozenblat, Cervantes, cuya relación con su esposa Catalina de Salazar y Palacios «era una vida de dos seres juntos, pero faltos de mutuo sentimiento... (7), critica la injusticia de la regla del matrimonio cristiano; agrega Rozenblat que en el aparentemente inofensivo género entremesil «...halló Cervantes un vehículo insospechable para indicar lo inhumano que podía ser (que puede ser), en ciertas condiciones sociales y afectivas, el vínculo del matrimonio cristiano" (Rozenblat, 7).

Por otra parte, Zimic afirma que «en este entremés se atreve Cervantes a poner en duda, asimismo con Erasmo, la justificación racional, moral, y religiosa de 'la indisolubilidad absoluta' del matrimonio" (22). Teresa Aveleyra Arroyo de Anda considera que Cervantes, por medio de un procedimiento cómico-humorístico, no sólo critica la injusticia de la indisolubilidad del matrimonio cristiano, sino que destruye el ideal del amor entre casados «para sustituirlo al fin, dentro de la más plena afirmación, por otro valor restringido, pero real y accesible» (166). Este va- 
lor es "la mutua y benevolente tolerancia» que encontramos en la pareja reconciliada (167). Randel no cree que el entremés tome una posición definitiva y considera que cualquier intento de descubrir el punto de vista del entremés con respecto al matrimonio cristiano termina en un callejón sin salida; el entremés frustra las estrategias interpretativas del lector, y por lo tanto, Randel llega a la conclusión de que la obra se convierte en un comentario sobre las dificultades de proveer una imagen fiel del mundo a través de la literatura (84).

Estamos de acuerdo con las posiciones que indican que hay una crítica a la aplicación inflexible de las normas del matrimonio cristiano, pero también sostenemos que el entremés apoya el ideal. Una lectura detenida del entremés como obra cómica corroborará nuestro juicio. Estamos de acuerdo con Randel en que en el entremés no se pasa un juicio categórico, sino que más bien se crea un debate entre las dos posiciones donde el moderador es el juez que tiene que dar una sentencia final que nunca pronuncia; Cervantes se acerca a la crítica de Erasmo del matrimonio, pero nos deja determinar nuestras propias conclusiones. Los dos polos, praxis/ideal, se encaran en un diálogo cuyo resultado es un perspectivismo ideológico. Un análisis de los mecanismos de la risa en la obra en tanto que práctica social abrirá una ventana interpretativa que revelará el vaivén de significados del entremés.

La risa desencadena un complejo proceso de desmitificación en el cual tanto el sistema hegemónico de valores como la realidad social se trivializan. Ya Spadaccini propone que los entremeses de Cervantes en general "presentan una postura crítica y desmitificadora frente a las ideologías dominantes y oficiales" (74). La risa crea un ambiente carnavalesco en el cual no es posible tomar en serio ni las normas ni su expresión práctica, pero que tampoco permite ignorarlas ${ }^{15}$. El proceso de desmitificación no es ni demoledor ni definitivo, sino que cuestiona el estado de cosas de la época.

Los críticos que mencionamos en los párrafos anteriores llegan a sus conclusiones a través de diferentes metodologías, pero sólo Aveleyra procede con exclusividad por medio de un análisis de la risa en la obra. Al analizar la risa, la mayoría de los críticos señalan los mecanismos más superficiales de la comicidad: inversión, automatización, contradicción. Aveleyra estudia el elemento cómico en más detalle y califica el mecanismo de la risa de la obra de "procedimiento cómico-humorístico o negativo-

\footnotetext{
is Eugenio Asensio ha sefialado la ascendencia carnavalesca del entremés (20).
} 
positivo» (166). El polo negativo consiste en la sátira de los personajes que desfilan por la obra por medio de la cual uel autor logra revelar la comicidad, a veces un poco triste y sórdida, de lo cotidiano: en este caso la vida conyugal y doméstican (167); el polo positivo es la alusión a la pareja reconciliada (167) y la moraleja de la canción final (168). Aveleyra llega a la conclusión de que esta técnica sirve para destruir el ideal del matrimonio cristiano y reemplazarlo por otro (166). No estamos de acuerdo con esta conclusión, pues creemos que el efecto trivializador de la risa corroe la inflexibilidad de la norma del matrimonio cristiano y no el ideal mismo.

Cervantes, espíritu no revolucionario sino más bien reformador, no quería ni podía echar por tierra toda la estructura del matrimonio cristiano, pero sí era capaz de poner en tela de juicio de una manera sutil el estado de cosas de su época. En el Siglo de Oro el entremés no se consideraba como género serio, y por lo tanto, en teoría, no se utilizaba como vehículo para presentar y discutir temas difíciles. Pero a la vez, dentro de este contexto en apariencia innocuo, se entrecruzan discursos dominantes y subversivos que afirman o ridiculizan la ideología hegemónica.

Según las teorías peninsulares del siglo xVI y xVII, herederas de las teorías de Aristóteles y Cicerón ${ }^{16}$, la risa tiene un blanco contra el cual se pronuncia un juicio. Afirma Alonso López Pinciano en su Philosophia antigua poética que

son muchos... los motiuos y muchos los lugares (que causan risa), porque la risa está fundada en vn no sé qué de torpe y feo, de lo cual ay en el mundo más que otra cosa alguna. Sea, pues, el fundamento principal que la risa tiene su assiento en fealdad y torpeza (33).

Francisco Cascales, que unos cuarenta años más tarde publica sus Tablas poéticas repite el mismo juicio: «Y Aristóteles dize que: 'Ridiculum est peccatum quoddam ex turpitudine sine dolore'. De aquí sacamos que la materia cómica hace mover a risa y que la risa es una burla sin dolor de alguna cosa torpe y fea" (221). Margaret Newels resume las teorías del siglo xVI y del xVII así: «la estética de lo cómico se basa en lo mismo: lo que ofende contra la proporción, la belleza, la armonía, y el decoro resulta ridículo y cae en la esfera de lo cómico" (88).

16 Margaret Newels considera que las teorias de la risa del Pinciano y de Cascales se acercan más a la de Cicerón: «esta fundamentación de la risa, así como la formulá 'turpidito et deformitas', procede del De Oratore de Cicerón (II, 58, 236) más bien que de la definición de Aristóteles... (90). 
El Pinciano deja claro que la fuente de la risa está tanto en los elementos físicos y fisiológicos como en las palabras: "quede, en suma, assentado que tanto es vna cosa ridícula, quanto participa de torpeza y fealdad en cierta forma, agora sea en obras, agora en palabras» (42). Que la risa no es sólo debida a acciones sino que también es ideológica lo comprueba el Pinciano con numerosos ejemplos; Fadrique en la Philosophía antigua dice:

De las partes de la oratoria se toman también argumentos de risa: $y$, ansí como los rhetóricos sacan sus argumentos para suadir, pueden los cómicos sacarlos para mouer a risa de los mismos lugares que la inuención da. De la difinición sea ejemplo el que difinió a la mujer diziendo: "La mujer es sarna del espíritu del hombre», queriendo dezir que, como la sarna trae inquietud al cuerpo, la mujer trae en dessassossiego al alma del hombre (45-46).

Consideran los teóricos del siglo XVI y XVII que la risa también tiene un efecto regenerativo, efecto que en el caso de $E l$ juez de los divorcios aliviaría la ansiedad que produce el conflicto irresoluble de la obra. Fadrique, en la Philosophia antigua del Pinciano, define la comedia, recordando la catarsis de Aristóteles, como "[la] 'imitación actiua hecha para limpiar el ánimo de las passiones por medio del deleyte y risa'" (17). Repite el tópico Cascales en sus Tablas poéticas afirmando que «la comedia es imitación dramática de una entera y justa acción humilde y suave que por medio del pasatiempo y risa limpia el alma de los vicios» (203). Insiste en la utilidad de la comedia asignando al 'poeta cómico' la tarea de adeleytar y mover a los oyentes con ridículas acciones" (205). Ambos teóricos están de acuerdo en que la risa tiene una función correctiva, función característica de los géneros cómicos, la cual le presta validez y prestigio a la risa dentro de una sociedad de tendencias moralizadoras.

La risa denota una actitud de superioridad, pues su blanco es aquello que se debe corregir y que está de acuerdo con la norma ${ }^{17}$. La risa se dirige contra lo que es reprensible desde el punto de vista de la ideología dominante. Fadrique afirma que el castigo para quien no encuentre cómicas las situaciones que menciona es reírse de él:

Para reyr son todos essos [ejemplos], no para llorar; y si dellos vos no os reys, merecéys que se ryan de vos. ¿Qué cosa más de reyr que ver

17 D. H. Munro afirma que toda teoría de la risa que se deriva de Aristóteles se puede considerar de degradación y de incongruencia, y que en el caso de degradación se basa en el sentimiento de superioridad del que se rie (83). 
a un moço, desollado de una ramera, lamentarse que le ha chupado su hazienda y salud? ¿Y qué cosa más de reyr que ver a la dama llorar de zelos a su amante? ¿Y qué más de reyr de ver los enredos de una alcahueta o rufián enmarañados para engañar el uno al otro? ¿Y q[ué] más de reyr de veer a vn sieruo malicioso lleno de temor y miedo que le han de apalear por algún embuste que hizo? ¿Y que más de reyr que veer a vn enamorado suspirando, la noche de Enero, en la calle y sazón elada, por la que está durmiendo a buen sueño y. si despierta, se está riendo dél? Si desto no os reys... que merecéys, digo otra vez, se ryan de vos (López Pinciano, 22-23).

La risa en este contexto toma un carácter de control social puesto que el individuo tiene que reírse de las situaciones consideradas cómicas so pena de que otros lo condenen y ridiculicen con su risa ${ }^{18}$.

El Pinciano y Cascales, de acuerdo con Aristóteles, sostienen que lo cómico no debe mezclarse con los sentimientos. En la Philosophia antigua, el Pinciano pregunta a Fadrique porque muchas veces no nos reímos de una cara fea; éste responde que "un cuerpo naturalmente feo y co[n]trahecho causa risa, lo que no haze causado por enfermedad, porque entra la co[m]passión, y no consiente entrada a la risa" (34). Como vimos, Cascales está de acuerdo pues para él "la risa es burla sin dolor..." (221). Si los oyentes lloran o sienten compasión en una comedia, concluye el Pinciano, es «o por demasiado sentido del oyente, o porque el poeta, dexando de guardar la perfección cómica, resualó en la trágica” (24).

Las ideas anteriores se pueden aplicar a El entremés del juez de los divorcios, con algunas reservas, para investigar la función de la risa en la obra. Cervantes va un paso más allá de los teóricos de la comicidad, pues en sus entremeses aparece un elemento de compasión que tanto Cascales como el Pinciano encontrarían inaceptable en una obra cómica. Por otra parte, sí existe en la risa cervantina un elemento de superioridad. Teniendo en consideración este elemento de superioridad, podríamos llegar a la conclusión de que el blanco de la risa en el entremés de Cervantes es claro, pues, si nos reímos de los querellosos personajes, entonces éstos deben ser feos -en el sentido de Cascales y del Pinciano-y por lo tanto inferiores a nosotros y dignos de nuestro desprecio. Pero también es ridículo e indeseable el divorcio, pues contra él de igual forma se dirige la risa. Al reírnos estamos expresando nuestro sentimiento de superioridad hacia los carica-

is Marcel Pagnol, en su libro Notes sur le rire, explica los efectos de la risa en grupo de la siguiente manera: «le rire étant l'expression d'un sentiment de supériorité, on ne veut pas être moins superieur que son voisin* (104). 
turescos personajes y hacia la idea del divorcio; la risa trivializa y destruye las peticiones de los malcasados.

Esta conclusión es en parte correcta, puesto que el entremés no acepta el divorcio como una opción perfecta, pero no tiene en cuenta el diálogo entre realidad e ideal que ocurre en la obra. Si nos reímos de los argumentos disparatados de los demandantes de divorcio, nos burlamos también de sus matrimonios intolerables, que se asemejan a la unión de las víboras entrelazadas del emblema de Soto; matrimonios como los que Erasmo critica y que la norma eclesiástica considera sacramentos a pesar de su falta de armonía. En otras palabras, la risa pone al descubierto la ironía que se crea al aplicar la norma de la indisolubilidad del matrimonio en el caso de matrimonios fracasados.

Llegamos, entonces, a un aparente callejón sin salida, a una tensión irresoluble que forma la base del alcance crítico del humor del entremés: nos reímos tanto del divorcio como de los matrimonios inarmónicos del entremés, pero la doctrina eclesiástica no permite solución alguna. Desde el punto de vista del Pinciano, esto quiere decir que ridiculizamos y juzgamos tanto al divorcio como a los matrimonios; junto con el juez del entremés, en medio de nuestra risa, dejamos las decisiones de divorcio para otro día evitando hacernos responsables de una situación que tiene profundas implicaciones humanas y sociales. Aunque al principio el juez rechaza la petición de divorcio del Vejete y de Mariana - «Pues yo no puedo hacer este divorcio, 'quia nullam invenio causam'» (102) - al final, tiene dudas y pospone su decisión: "Mirad, señores: aunque algunos de los que aquí estáis habéis dado algunas causas que traen aparejada sentencia de divorcio, con tode eso, es menester que conste por escrito, y que lo digan testigos; y así, 'a todos' os recibo a prueban (109) (la cursiva es nuestra).

Detengámonos ahora en el mecanismo de la risa del texto dramático de $E l$ juez de los divorcios. Como mencionaba más arriba, la risa de este entremés no es el resultado de payasadas, golpes, ni porrazos. Su fuente radica en la ambigüedad ideológica expresada por el diálogo y por su ritmo sosegado. Las quejas de los cónyuges que desfilan por la obra pidiendo el divorcio entablan un diálogo que a veces parece una serie de monólogos entretejidos por el juez quien actúa como centro y monitor. El conflicto de voluntades, las razones de cada personaje, sus respuestas y reacciones, y la imposibilidad de dar una solución hacen reír. Estos agitados y conflictivos intercambios verbales son feos a lo Pinciano, porque muestran una faceta disparatada de las relaciones marido-mujer. 
La risa comienza en el primer cuadro cuando salen Mariana y el Vejete discutiendo:
Mariana. ...Desta vegada tengo que quedar libre de pedido y alcabala, como el gavilán.
VEJETE. Por amor de Dios, Mariana, que no almonedees tanto tu nego- cio; habla paso, por la pasión que Dios pasó; mira que tienes atronada toda la vecindad con tus gritos; $\mathbf{y}$. pues tienes delante al señor juez, con menos voces le puedes informar de tu justicia (97-98).

La mujer gritona, motivo común de risa, que vocifera sus problemas matrimoniales frente a todo el barrio se une al humor verbal del Vejete para producir un ambiente festivo que marcará toda la obra y predispondrá a la audiencia para reírse. Este encuentro entre marido y mujer, típico del resto del entremés, abre el conflicto irresoluble de la obra entre matrimonios inarmónicos y la doctrina del divorcio. Incluye también un tipo de humor verbal más superficial que se alimenta de juegos de palabras (paso/pasión/pasó); tales juegos de palabras son importantes porque crean el ambiente que permite el éxito del resto de los elementos más sutiles productores de risa ${ }^{19}$.

Mariana, ridiculizada por su comportamiento, sirve de vehículo, a primera vista inofensivo, para expresar el desacuerdo con la posición del Concilio de Trento sobre el matrimonio:

En los reinos y en las repúblicas bien ordenadas, habia de ser limitado el tiempo de los matrimonios, y de tres en tres años se habían de deshacer, o confirmarse de nuevo, como cosas de arrendamiento, y no que hayan de durar toda la vida, con perpetuo dolor de entrambas partes (98).

¿Sería acaso una referencia a las repúblicas protestantes, como lo sugiere Spadaccini? ${ }^{20}$ o ¿sería quizás una alusión al comentario de Erasmo sobre el matrimonio? En cualquier caso, la risa ridiculiza y resta validez a tal propuesta, sobre todo al salir de boca de Mariana, pero, a la vez, "no deja que surja algún interrogante en la mente del público (ese público lector, culto, que sabe 'ver de espacio lo que pasa apriesa') que se atreve a pensar» (Spadaccini, 26).

Más intercambios verbales cómicos como los de Mariana con el Vejete se darán durante toda la obra entre las otras parejas. Guiomar le dice al juez con respecto a su marido el soldado:

19 ERICK Bentley ha señalado que para estudiar la risa se debe considerar toda la curva de la cual la carcajada es sólo el resultado final (234).

20 "La referencia a 'las repúblicas bien ordenadas' podría ser una alusión a los paises 'reformados', esos mismos donde, según Ricote (Don Quijote, II, 54), se vivia con 'libertad de conciencia' (SPAdaccinI, 27). 
Guromar. ¡Bendito sea Dios!, que se me ha cumplido el deseo que tenía de verme ante la presencia de vuesa merced, a quien suplico, cuando encarecidamente puedo, sea servido de descasarme déste.

JuEz. ¿Qué cosa es déste? ¿No tiene otro nombre? Bien fuera que dijérades siquiera: «deste hombre».

Guiomar. Si él fuera hombre, no procurara yo descasarme.

Juez. Pues, ¿qué es?

Guiomar. Un leño (102).

La implícita acusación de impotencia intensifica el ambiente cómico en que los personajes se hacen irrisorios, pero a la vez, por ser razón válida para el divorcio, le presta credibilidad a la petición de Guiomar ${ }^{21}$.

El antagonismo de esta pareja se continúa con el del Cirujano y Minjaca:

Cirujano. Por cuatro causas bien bastantes, vengo a pedir a vuesa merced... haga divorcio entre $\mathrm{mf}$ y la señora... Minjaca.

JuEz. Resoluto venis; decid las cuatro causas.

Cirujano. La primera, porque no la puedo ver más que a todos los diablos; la segunda, por lo que ella se sabe; la tercera, por lo que yo me callo; la cuarta porque no me lleven los demonios, cuando de esta vida vaya, si he de durar en su compañía, hasta mi muerte.

Minjaca. Señor juez, vuesa merced me oiga, y advierta que, si mi marido pide por cuatro causas divorcio, yo le pido por cuatrocientas. La primera..., etc. (106-107)

Aun en el caso del soliloquio del Ganapán, quien presenta otra causa justa de divorcio - haberse casado borracho-, tiene lugar un diálogo implícito pues se siente la presencia de la figura de la esposa, como lo observa Henri Recoules, quien cree que la placera se agarraría a golpes con las otras mujeres si saliera a escena ${ }^{22}$ :

Ganapan. ...estando una vez muy enfermo de los vaguidos de Baco, prometí de casarme con una mujer errada... ha salido tan soberbia y de tan mala condición que nadie llega a su tabla con quien no riña, ora sobre el peso falto, ora sobre que le llegan a la fruta, y a dos por tres les da con una pesa en la cabeza, o adonde topa, y las deshonra hasta la cuarta generación, sin tener hora de paz con todas sus vecinas ya parleras (108).

${ }^{21}$ Hay varias causas que permiten la anulación del matrimonio, entre ellas la impotencia. Ver OLSEN (18).

22 . Nul doute que, si Cervantes l'avait admise à comparaître devant le juge, elle aurait cherché querelle à l'une des harpies: doña Guiomar, Mariana, ou Aldonza de Minjaca et l'intermède au lieu de se terminer en chansons aurait été couronné par des coups!» (Recoules, 153). 
El entremés presenta dos casos donde hay causas válidas para pronunciar sentencias de divorcio - impotencia y embriaguez-, pero lo hace dentro de un ambiente jocoso en donde las carcajadas velan la crítica. Estos diálogos dramáticos se entrelazan para producir una risa de la que resulta la ridiculización de los personajes y la desmitificación de su situación, con la ayuda del necesario sentimiento de superioridad del público, y de la condensación del elemento jocoso en intercambios cada vez más cortos. Sin embargo, ignorando las reglas del Pinciano y de Cascales, Cervantes introduce un elemento de compasión a través de los malcasados que recuerdan a las víboras de Soto condenadas a atacarse toda la vida.

Vemos, pues, que desde un principio la risa contribuye a la construcción de la ambigüedad del entremés; el conflicto central de la obra - las contiendas entre los cónyuges - es el blanco de la risa. Aunque algunas de estas contiendas tienen su justificación y su valor -el juez dice que «algunos de los que aquí estáis habéis dado algunas causas que traen aparejada sentencia de divorcion (109) - , la risa las trivializa creando la ambigüedad ideológica del texto. Pero a la vez que nos reímos de las peticiones de divorcio, nos reímos de los matrimonios disparatados pero indisolubles; las peleas entre cónyuges no deberian existir en una sociedad en que el matrimonio ideal es un lazo que sólo la muerte separa. La risa actúa en su poder de arma de doble filo: el oyente o lector cuidadoso puede detenerse y meditar sobre los casos patéticos que desfilan por la obra y concluir que las leyes eclesiásticas sobre el divorcio quizás sean demasiado inflexibles.

La pareja de diciembre y abril, Guiomar y su soldado perezoso y tal vez impotente, la pareja del cirujano y su esposa con sus cuatrocientas quejas, y el ganapán que se casa en medio de una embriaguez con la placera son ejemplos de la tensión entre el ideal del matrimonio y su aplicación práctica. La risa nos recuerda sin interrupción, no sólo el conflicto entre las parejas, sino entre una realidad social insoportable y un ideal inflexible. Si el objetivo de la risa del entremés es el de afirmar de manera categórica la validez de la indisolubilidad del yugo matrimonial como lo ha querido parte de la crítica, entonces el entremés no tiene éxito, pues nos deja un sabor amargo y dudas en el espíritu ${ }^{23}$.

${ }^{23}$ Aqui se aleja Cervantes de las teorías del humor de base aristotélica que proponen que los sentimientos no tienen cabida en la comedia. Cervantes está, sin lugar a dudas, unos pasos adelante de los teóricos de la época: «Comedy is a living and evolving form, always changing a shade faster than the defintions which pursue it» (Donaldson, 1). 
Podríamos decir, entonces, que el irónico refrán de la canción final que tanto ha causado dolores de cabeza a la crítica - "más vale el peor concierto,/que no el divorcio mejor» (110)en vez de contradecir el resto de la obra, refleja su ambigüedad; al no encontrarse solución alguna, se prefiere al divorcio un concierto insatisfactorio. A primera vista, este refrán es portavoz de la ideología dominante de la España del siglo xvII que quiere mantener el matrimonio a toda costa, pero lleno de ironía, señala que tal solución, como lo sugiere Zimic (22), no es siempre satisfactoria. La ironía del refrán corresponde a la del resto de la obra donde la risa ridiculiza las peticiones de divorcio pero que a la vez deja entrever lo disparatado de los matrimonios en cuestión.

La obra se divide en cinco situaciones. La petición de Mariana y el Vejete, la de Guiomar y el Soldado, la del Cirujano y Minjaca, la del Ganapán, y una quinta situación que cierra el entremés con la entrada de los músicos que tocan la canción final. Contrastan las cuatro primeras situaciones con la quinta: mientras que en las primeras cuatro aparecen parejas desavenidas, en la quinta se hace referencia a una pareja reconciliada que podría representar el ya mencionado ideal de reconciliación expresado en la Primera Epístola de los Corintios (1 Cor. vii 10-12). Dos músicos interrumpen el entremés en el momento en que el juez decide posponer su decisión:

Músıcos. Señor juez, aquellos dos casados tan desavenidos que vuesa merced concertó, redujo y apaciguó el otro día, están esperando a vuesa merced con una gran fiesta en su casa; y por nosotros le envían a suplicar sea servido de hallarse en ella y honrallos (109).

Se puede llegar a la conclusión, correcta pero incompleta, de que este final muestra la manera decente de actuar, esa manera a la que se refiere Aveleyra de reconciliación y tolerancia (167), en contraste con la incorrecta, las quejas y peleas del resto de la obra. Un análisis de la risa nos permitirá ir más allá de estas conclusiones.

La risa predomina en las primeras cuatro situaciones del entremés, mientras que es mínima en la última - no nos reímos de la pareja reconciliada - y cuando la risa reaparece es para ridiculizar los divorcios, a los demandantes y a los oficiales:

Procurador. Desa manera, moriríamos de hambre los escribanos y procuradores desta audiencia; que no, no, sino todo el mundo ponga demandas de divorcios, que al cabo, al cabo, los más se quedan como se estaban, y nosotros habemos gozado del fruto de sus pendencias y necedades (109). 
Tenemos, pues, un incremento y concentración de la risa desde el principio de la obra que se ve truncado de repente con la entrada de unos músicos que son portavoces de los ideales establecidos. Ya no estamos en un ambiente festivo, ya no nos reímos, sino que a manera de descanso, oímos a los músicos con cierta seriedad. Pero esta ausencia de risa no quiere decir que el entremés acepte de manera total la reconciliación; la ausencia de la risa indica que estamos ante una situación seria. Es lógico no reírse al final, pues la situación es grave: el ideal de armonía nunca aparece en escena. Nunca nos reímos de la pareja reconciliada mencionada por los músicos convalidando así el ideal; pero a la vez estos reconciliados, representantes del ideal, nunca entran a escena y se convierten en símbolos lejanos de un ideal inalcanzable. En contraste, resuenan en nuestros oídos las quejas de las parejas desavenidas que están todavía frente a nuestros ojos; la risa los hace reales. Tanto la presencia como la ausencia de la risa ayudan así a establecer un diálogo entre ideal y praxis que no lleva a una síntesis, pero que da voz a preocupaciones e inquietudes.

Dentro de este contexto se entiende el alcance de la canción final. Aunque el juez niegue al comienzo el divorcio a la primera pareja - «pues yo no puedo hacer este divorcio, quia nullam invenio causam» (102) -, nunca da su decisión: "Mirad señores: aunque algunos de los que aquí estáis habéis dado algunas causas que traen aparejada sentencia de divorcio, con todo eso, es menester que conste por escrito, y que lo digan testigos; y así, a todos os recibo a prueban (109). El juez no puede dictar una sentencia final. Tampoco lo hacen ni el entremés, ni el público, ni el lector culto que se encuentran en un callejón sin salida entre malos matrimonios y divorcio. La canción con su refrán - «que vale el peor concierto/más que el divorcio mejor»-, no le ayuda al juez a dictar una decisión pues no hace más que exponerle, en toda su ironía, el dilema moral ante el que se encuentra: un ideal lejano y una realidad presente.

Este juez nunca habría podido dictar una sentencia. Dentro de un entremés de poco movimiento, hay un juez aun más estático que el resto de los personajes: "Aun bien que está ya el señor juez de los divorcios sentado en la silla de su audiencia” (97), dice Mariana al principio de la obra. Así queda sentado e inmóvil durante el resto del entremés. Este juez se convierte en el símbolo estático del orden y de la autoridad. Pero el juez es una autoridad ineficaz que no puede resolver el problema moral de la obra, porque éste seguirá irresoluble mientras no se haga más flexible la posición eclesiástica sobre el divorcio. Del juez no nos 
reímos, tal vez porque no debemos reírnos directamente de la autoridad, o porque no vale la pena reírnos de ella. Este juez entronca con la tradición popular que, como señala Maxime Chevalier (43), siendo pobre, se reduce a una desconfianza de la honradez de los jueces. A la autoridad que representa el juez tampoco se le puede tener confianza y, así, por falta de credibilidad, el juez no puede dar una solución final.

Desfilan en El juez de los divorcios una serie de parejas desavenidas que encarnan la dolorosa realidad que puede resultar de la aplicación inflexible de la norma eclesiástica del matrimonio; se menciona también, sin que aparezca ante nuestros ojos, un ejemplo del ideal de la Primera Epístola de los Corintios: la pareja reconciliada. Un análisis de la risa en El juez de los divorcios revela una ambigüedad ideológica en que la risa es la guía que nos lleva del plano social al ideal sin permitirnos ningún descanso en un lugar fijo. El cuadro de las parejas-víboras, entrelazadas hasta la muerte, suscita tanto compasión como risa, llevándole la contraria a las recetas del Pinciano y de Cascales para crear una buena obra cómica. Este cuadro se constituye en una crítica velada de la doctrina eclesiástica del divorcio que coincide con la más abierta crítica erasmiana. Erasmo sostiene que el matrimonio es un espejo de la unión de Cristo con la Iglesia y que por lo tanto es de carácter sacramental; el divorcio no es disonante dentro de esta concepción del matrimonio, pues ayudaría a deshacer uniones conyugales inarmónicas que no reflejan la unión de Cristo y la Iglesia (112-113) ${ }^{24}$. ¿Qué uniones más alejadas del ideal -se preguntaría el lector culto- que aquellas presentadas en El entremés del juez de los divorcios? El entremés no resuelve el conflicto entre malos matrimonios y divorcio, sino que apoya el ideal del matrimonio cristiano y se constituye en una crítica de la práctica inflexible de la norma en el siglo xvir.

En el entremés, como en el carnaval, se presenta un mundo al revés, en el que se intuye un mundo al derecho. Pero El juez de los divorcios va un paso más allá porque su mundo al revés corresponde a la realidad social de la época, y su mundo al derecho a un ideal inalcanzable. Al contrario de los festivales que invierten la norma y que tienden a reforzar y preservar la sociedad ${ }^{25}$,

24 *...in the copelynge together of man and wife... is represented unto us a certayne fygure, and ymage of Christs iuyninge his spose unto hymselfe, whiche is the churche. And truly matrymonye beynge well kept, is a very godly, and holy thyng” (ERASMO, 112).

25 IAN Donaldson explica que los festivales en donde de manera temporal se invierte la norma tienden a reforzar y a preservar la sociedad más que a atacarla (14-15). 
el desfile frenético de los personajes del entremés cervantino pone la ideología del siglo xvir en tela de juicio. Ese vaivén entre dos planos y el cuestionamiento sutil de la norma le presta al efecto cómico del entremés una profundidad que lo coloca al nivel de lo mejor del humor de Cervantes ${ }^{26}$.

\section{Pablo Restrepo-Gautier UNIVERSITY OF BRITISH COLUMBIA}

\section{OBRAS CITADAS}

Agostini, Amelia, «El teatro cómico de Cervantes», BRAE, 44, 1964, 475-540.

Asensio, Eugenio, Itinerario del entremés. Madrid, Gredos, 1965.

Aveleyra ARroyo de ANDA, Teresa, El humorismo de Cervantes en sus obras menores. México, Imprenta Aldina, 1962.

Aviles, Miguel, Erasmo y la inquisición: el libelo de Valladolid y la Apología de Erasmo contra los frailes españoles. Madrid, Fundación Universitaria Española, 1980.

Bataillon, Marcel, "Cervantes y el matrimonio cristianon, en Varia lección de clásicos españoles. Madrid, Gredos, 1964, 238-255.

Bentley, Erick, The Life of Drama. New York, Atheneum, 1964.

Casalduero, Joaquin, Sentido y forma del teatro de Cervantes. Madrid, Aguilar, 1951.

Cascales, Francisco, Tablas poéticas. Madrid, Espasa-Calpe, 1975.

Cervantes, Miguel De, Entremés del juez de los divorcios. Entremeses., ed. Nicholas Spadaccini. Madrid, Cátedra, 1982, 97-110.

Chevalier, Maxime, Tipos cómicos y folklore: siglos XVI-XVII. Madrid, EDI-6, 1982.

Donaldson, IAN, The World Upside-Dowr: Comedy from Jonson to Fielding. Oxford, Clarendon Press, 1970.

Erasmo, Desiderio, The Censure and Iudgement of the Famous Clark Erasmus of Roterdam: Whyther dyuorsement betwene man and wyfe stondeth with the lawe of God... in the Book of Annotations, upon these words of Paul, trans. Nicholas Lesse. London, 1550?

López Pinciano, Alonso, Philosophia antigua poetica. Tomo 3. Madrid, Biblioteca de autores de antiguos libros hispánicos, 1959.

MunRo, D. H., Argument of Laughter. London, Cambridge University Press, 1951.

Newels, Margaret, Los géneros dramáticos en las poéticas del Siglo de Oro. Londres, Tamesis Books, 1959.

OLSEn, V. Norskov, The new Testament Logia on Divorce: a Study of their interpretation from Erasmus to Milton. Tübingen, J.C.B. Mohr, 1971.

PAgnol, Marcel, Notes sur le rire.'París, Editions Nagel, 1947.

RANDel, MARY GAYLORd, aThe Order in the Court: Cervantes' Entremés del juez de los divorcios», Bulletin of the Comediantes, 34.1, 1982, 83-95.

${ }^{26}$ La versión inicial de este artículo se presentó en el *Thirteenth Annual International Golden Age Spanish Drama Symposium* en El Paso, Texas, celebrado en marzo de 1993. 
Recoules, Henri, «Les personnages des intermèdes de Cervantès*. Anales Cervantinos, 10, 1971, 51-168.

Rozenblat, W., "¿Por qué escribió Cervantes El juez de los divorcios? \# Anales Cervantinos, 12, 1973, 129-134.

Ruiz-Galvez Priego, Estrella, Statut socio-juridique de la femme en Espagne au XVIème siècle: Une étude sur le marriage chretien faite d'après l'épitome de Matrimonio de Diego Covarrubias y Leyva, la legislation royale et les moralistes. París, Didier Erudition, 1990.

Soto, Hernando DE, Emblemas moralizadas, ed. Carmen Bravo-Villasante. Madrid, Fundación Universitaria Española, 1983.

Spadaccini, Nicholas. Introducción. Cervantes. Entremeses. Madrid, Cátedra, 1982.

Telle. Emile V., Érasme de Rotterdam et le septième sacrement: Étude d'évangélisme matrimonial au XVI siècle et contribution à la biographie intellectuelle d'Érasme. Ginebra, Librarie E. Droz, 1954.

Zimic, Stanislav, "El juez de los divorcios de Cervantes*, Acta Neophilologica, 12, 1979, 2-24. 